\title{
ORIENTACÕES GERAIS PARA UMA GASTRONOMIA SUSTENTÁVEL
}

\author{
GENERAL GUIDELINES FOR A SUSTAINABLE GASTRONOMY
}

ORIENTACIONES GENERALES PARA UNA GASTRONOMÍA SOSTENIBLE

Dr. Prof. Rodolfo W. Krause

Universidade do Vale do Itajaí rodolfo@univali.br

\section{Grad. Álvaro A. D. S. M. Bahls}

alvarobahls@gmail.com

Data de Submissão: 02/05/2013

Data de Aprovação: 06/08/2013

\section{RESUMO}

Atualmente, a sustentabilidade tomou grandes proporções no âmbito científico, governamental e acadêmico. Está-se mais ciente e preocupado com o meio ambiente, percebeu-se que este é importante e indispensável, além de, em muitos aspectos, esgotável. Usar de recursos naturais sem prudência é colocar em risco o bem-estar de futuras gerações. Dentro desse contexto, o objetivo principal desse artigo é trazer, para o âmbito nacional, a definição e a discussão dos principais aspectos que podem tornar a gastronomia em uma atividade sustentável, discutindo-se sobre a elaboração de cardápios sustentáveis; escolha de matérias-primas; aspectos de construção; ensino e treinamento. O objetivo secundário é ampliar a discussão sobre a sustentabilidade no meio gastronômico, mostrando o panorama nacional, as tendências e as práticas internacionais. A metodologia utilizada foi uma pesquisa bibliográfica, reunindo artigos científicos, dissertações e teses acadêmicas relacionadas à gastronomia sustentável. Conclui-se que a gastronomia sustentável é extremamente importante para o turismo e tem grande impacto na sustentabilidade global. No Brasil, o assunto está em estágio primário, os estudos são escassos, assim como os empreendimentos conscientes e ativos nessa área. O presente artigo contribui com uma reunião dos principais aspectos relacionados à sustentabilidade dentro da experiência gastronômica turística, fomentando a discussão sobre sustentabilidade e auxiliando o restaurador a aderir a algumas práticas consideradas sustentáveis.

PALAVRAS-CHAVE: Gastronomia. Sustentabilidade. Gastronomia sustentável.

\begin{abstract}
Nowadays, sustainability is a major part of the scientific, governmental and academic agenda. We are more aware and concerned about the environment, perceiving its essentiality to our lives and many respects its exhaustibility. Indiscriminate use of resources will endanger the welfare of future generations. Within this context, the primary goal of this paper is to bring to the Brazilian academic realm some definitions and discussions of the main aspects of sustainable gastronomy. It addresses and discusses the development of sustainable menus, the choice of raw materials, aspects of construction, and education and training. The secondary goal was to widen the discussion about sustainability in gastronomy, showing the national context of Brazilian gastronomy in comparison with some aspects seen internationally. The methodology used for the article was a specialized literature review, gathering scientific articles, dissertations and academic thesis related to the subject in question. We conclude that gastronomy is extremely important for sustainable tourism, and has a major impact on global sustainability. In Brazil, this subject is still incipient, studies are lacking, as are conscious and active entrepreneurs in this area. This article contributes to the
\end{abstract}


gathering of the main aspects that make gastronomy a sustainable practice, promoting the discussion about sustainability and giving the restaurateur some general guidelines.

KEYWORDS: Gastronomy. Sustainability. Sustainable Gastronomy.

\section{RESUMEN}

Actualmente la sostenibilidad asumió grandes proporciones en el ámbito científico, gubernamental y académico. Hay más conciencia y preocupación por el medio ambiente, se percibió que este es importante e indispensable y además, en muchos aspectos, finito. Usar recursos naturales sin prudencia es poner en riesgo el bienestar de futuras generaciones. Dentro de ese contexto, el objetivo principal de este artículo es traer para el ámbito nacional la definición y el debate de los principales aspectos que pueden transformar a la gastronomía en una actividad sostenible, discutiendo acerca de la elaboración de menús sostenibles; elección de materias primas; aspectos de construcción; enseñanza y entrenamiento. El objetivo secundario es ampliar la discusión sobre la sostenibilidad en el medio gastronómico, mostrando el panorama nacional, las tendencias y las prácticas internacionales. La metodología utilizada fue una investigación bibliográfica, reuniendo artículos científicos, disertaciones y tesis académicas relacionadas a la gastronomía sostenible. Se concluye que la gastronomía sostenible es extremadamente importante para el turismo y ejerce un gran impacto sobre la sostenibilidad global. En Brasil el asunto está en un estadio primario, los estudios son escasos, así como los emprendimientos conscientes y activos en esa área. El presente artículo contribuye con una reunión de los principales aspectos relacionados a la sostenibilidad dentro de la experiencia gastronómica turística, fomentando la discusión sobre sostenibilidad y auxiliando al restaurador a adherir a algunas prácticas consideradas sostenibles.

PALABRAS CLAVE: Gastronomía. Sostenibilidad. Gastronomía sostenible.

\section{INTRODUÇÃO}

O aquecimento global é serio demais para o mundo continuar a ignorar seus perigos ou dividir-se em facções opostas a seu respeito. (TONY BLAIR, Setembro de 2005).

O clima na terra está em constante mudança, levando bilhões de anos para adequar-se ao ecossistema habitável e equilibrado que se possui hoje. Percebeu-se que o ser humano é parte ativa desse ecossistema e, desde que o aquecimento global passou a ser aceito pela maior parte da sociedade científica (PNAS, 2001), o único debate que pode ser válido é se se possui algum impacto nessa mudança. Na verdade, as pesquisas mais recentes afirmam que o aquecimento global é causado, em sua maior parte, pela atividade humana e pelas altas emissões de gases que aumentam o efeito estufa (HANSEN et al., 2006). Assim, os conceitos de sustentabilidade nunca estiveram tão presentes, pois se nota que nosso modo de vida possui consequências profundas na propagação de nossa espécie.

Desde a revolução industrial, a humanidade desenvolve-se aceleradamente e relativamente despreocupada com o meio ambiente, focando-se, principalmente, na produção e nos resultados (MASLIN, 2009). Nossa civilização possui seus alicerces em bens naturais não renováveis, principalmente em petróleo. Toda fonte de petróleo possui características similares quanto à sua durabilidade. Primeiramente, a fonte é descoberta, a extração é implantada, um pico de produção é atingido, seguido por um declínio e, inevitavelmente, seu término (HUBBERT, 1956). Resumidamente, a equação é simples: a alocação de petróleo da terra é finita e a demanda continua a crescer ao passar do tempo. O resultado é o eventual esgotamento das fontes petrolíferas, resultando no Peak Oil (HIRSCH et al., 2005).

Este é o atual desafio: o desenvolvimento por um longo período com qualidade de vida estável para a maioria da população atual e futura, sem exaurir os recursos naturais do planeta. Não é uma 
tarefa fácil, mas a raça humana é surpreendente por ter se adaptado e evoluído. Deve-se encarar, assim, o desafio do aquecimento global e da sustentabilidade com consciência e responsabilidade. Os conceitos de sustentabilidade foram criados a fim de desenvolver a humanidade sem prejudicar os recursos naturais que a sustentam, melhorando a qualidade social e mantendo a estabilidade econômica (WCED, 1987).

De acordo com a Organização Mundial de Turismo, esta atividade que gera receita anual superior ao PIB de alguns países desenvolvidos possui grandes impactos climáticos, já que os meios de transportes utilizados, a infraestrutura e os serviços consomem recursos e produzem impactos ambientais na mesma proporção. O turismo sustentável vem ao encontro dessa demanda vital de satisfazer às necessidades dos turistas e dos destinos turísticos, protegendo-os para o futuro (UNWTO, 2012). O desenvolvimento do turismo em determinadas regiões pode ter profundos impactos em sua proteção. Se este não for planejado sustentavelmente pode até extinguir um ecossistema. Por outro lado, o turismo tem potencial para trazer benefícios econômicos que apoiem a conservação natural, cultural e econômica de uma região ou país.

A gastronomia possui um peso grandioso dentro da atividade turística, tanto cultural quanto econômico (YURTSEVEN, 2011). Em um plano mais amplo, sabe-se que a alimentação tem papel fundamental na vida do ser humano. Em sua forma mais básica, é uma troca de matéria e energia entre as mais diversas espécies (SCHOENEMANN, 2006). Atualmente, a gastronomia toma outras proporções, possuindo aspectos sociais, lúdicos, artísticos e de saúde. O impacto da agricultura extensiva sobre o meio ambiente é altíssimo. Precisa-se, assim, reavaliar a maneira como se come. A gastronomia, sendo a forma mais evoluída do ser humano relacionar-se com o seu alimento, tem o papel de aproximar a sociedade global; promover sustentabilidade por meio da produção de alimentos locais, da biodiversidade, transmitindo conhecimentos, promovendo, consequentemente, o bem-estar social, principalmente dentro da atividade turística (SCARPATO, 2002).

O principal objetivo deste estudo é demonstrar que a gastronomia pode influenciar beneficamente na atual condição climática, no bem-estar social e de ecossistemas, mantendo sua viabilidade econômica. O objetivo secundário deste artigo é ampliar a discussão sobre assuntos ainda não abordados pelos restauradores brasileiros, mostrando o panorama nacional e as tendências e as práticas internacionais.

Dentro desse contexto, realizou-se um levantamento da atual condição da gastronomia sustentável nacional em termos de estudos científicos e por meio de nossa experiência, no intuito de mostrar ao restaurador algumas variáveis que podem ajudá-lo a aderir à gastronomia sustentável. A metodologia utilizada foi uma revisão bibliográfica que reuniu artigos científicos, dissertações e teses acadêmicas relacionadas à gastronomia sustentável escritos no Brasil e no exterior. Foram utilizadas pesquisas da base de dados EBSCO, da Biblioteca Nacional de Teses e Dissertações (BTDT) e do site de busca e pesquisa Google. O período desta pesquisa deu-se entre setembro de 2012 a dezembro de 2012. As buscas resultaram em um total de 37 artigos relacionados aos assuntos propostos. As palavras-chave utilizadas para essa pesquisa foram: gastronomia, sustentabilidade, desenvolvimento sustentável, ecogastronomia, gastronomia sustentável, turismo sustentável, construção sustentável, dentre outras. Foi então realizada uma revisão desse material, visando encontrar os fatores, comuns em vários artigos, que poderiam vir a influenciar a noção de gastronomia sustentável.

Essa revisão foi realizada sob o aspecto de uma análise qualitativa, a qual não tem relação com um modelo de referência ou paradigma. De acordo com os achados da pesquisa bibliográfica, as quatro variáveis seguintes, referentes às etapas da análise desta revisão, são as mais importantes para uma atividade gastronômica sustentável:

- elaboração de cardápios - dentro dessa variável, os seguintes subgrupos foram mencionados: tamanho das porções, sazonalidade e aspectos culturais;

- ingredientes - os seguintes subgrupos foram considerados: eficiência na produção, na embalagem e na estocagem; transporte; localidade-autenticidade; biodiversidade; técnicas para evitar desperdício e características nutricionais;

- construção de espaços físicos - discorre-se, em termos gerais, sobre o uso de energia renovável, a construção planejada com sustentabilidade, o uso de equipamentos mais eficientes e o manejo dos resíduos sólidos; 
- educação ambiental - engloba o papel das instituições educacionais e a eficiência na produção e no serviço por meio do treinamento da mão de obra, a fim de executar as diretrizes abordadas anteriormente.

No entanto, antes do aprofundamento em sustentabilidade gastronômica, deve-se, primeiramente, esclarecer os principais motivos que levaram a esse conceito. De acordo com o Intergovernmental Panel on Climate Change ${ }^{1}$ (IPCC), uma das causas que colocou a humanidade em direção à sustentabilidade é o aquecimento global. Em 2007, o IPCC foi reconhecido com o Prêmio Nobel da Paz. Sua conclusão sobre o assunto é que:

\begin{abstract}
O aquecimento do sistema climático e inequívoco, pois agora é evidente a partir de observações no aumento da temperatura média da terra e dos oceanos, derretimento em larga escala do gelo polar e glaciares e do aumento médio do nível do mar [...] A tendência linear do aquecimento dos últimos 50 anos de 1956 a 2005 é aproximadamente o dobro do que nos últimos 100 anos. (IPCC, 2007, p. 30).
\end{abstract}

A National Academy of Science (NAS), fundada em 1863, afirma que "[...] a mudança climática está ocorrendo [...] a média da temperatura da superfície terrestre aumentou cerca de $0.8^{\circ} \mathrm{C}$ nos últimos 100 anos, e cerca de $0.6^{\circ} \mathrm{C}$ desse aquecimento ocorrendo apenas nas ultimas três décadas" (THE NATIONAL ACADEMIES PRESS, 2011, p. 21). Essa é a mesma conclusão alcançada pelos estudos e pelas pesquisas feitas pela National Aeronautics and Space Administration (NASA), publicada por Hansen et al. (2006), como demonstra o Gráfico 1.

Gráfico 1 - Média da mudança da temperatura mundial entre 1880 e 2011

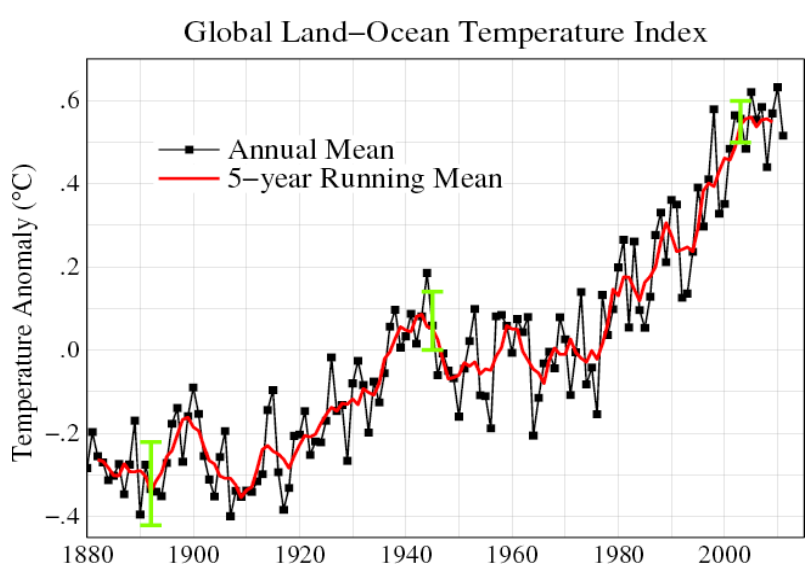

Fonte: NASA (2013).

Uma declaração foi assinada pelas Academias Nacionais de Ciência dos países do grupo G8+5 (as oito nações detentoras das maiores economias mundiais, mais o Brasil, China e Índia, resultando nos onze maiores emissores de gases causadores do efeito estufa), a qual define que "[...] há, agora, fortes evidências que um significante aquecimento global está acontecendo. É muito provável (acima de $90 \%$ de chance - de acordo com o Tratado de Incerteza) que a maioria deste aquecimento nas recentes décadas pode ser atribuída a atividades humanas" (PNAS, 2001). Sustentabilidade pode ser proposta como uma questão existencial, pois, segundo Prugh e Assadourian (2003, p. 13), "[...] em todos os níveis, a sobrevivência da raça humana está ameaçada pela nossa relutância em abraçar a sustentabilidade". Portanto, incentivar uma mudança filosófica, desde a infraestrutura até os serviços, para que empreendimentos gastronômicos ligados ao turismo ajudem a maximizar o bem-estar social e econômico, é parte importante dentro de uma gastronomia voltada à sustentabilidade.

O conceito moderno de sustentabilidade foi criado após a Conferência de Estocolmo sobre o Ambiente Humano, em 1972, realizada devido à crescente conscientização sobre o aquecimento global, resultando em uma organização para fomentar os estudos sobre o meio ambiente. A Brundtland Commission definiu Desenvolvimento Sustentável (DS) como aquele que supri as necessidades atuais sem impedir futuras gerações de satisfazerem as suas (WCED, 1987).

Em definições do DS contemporâneo, percebe-se a menção de três dimensões: econômica, ecológica e social - dimensões essas que são consideradas os três pilares do desenvolvimento 
sustentável (ELKINGTON, 1997). Observa-se, ainda, que a preocupação com a situação ambiental deve ser abordada de uma forma ativa e direta. Assim sendo, a fim de realizar avanços concretos dentro da gastronomia sustentável, as empresas devem preparar três linhas de reflexão e ação. A tradicional linha de lucro, o "proveito" da empresa; a linha de ação, que presta conta às "pessoas" de uma empresa e comunidade, formando uma organização socialmente responsável em suas operações; e a terceira, que se refere ao "planeta". Logo, o desenvolvimento sustentável dentro da gastronomia pode estar baseado nos três "Ps" propostos por Elkington (1997): proveito, pessoas e planeta, tendo como objetivo medir o desempenho financeiro, social e ambiental de um empreendimento gastronômico ligado ao turismo.

De acordo com a Organização Mundial de Turismo (2012), se se somar o Produto Interno Bruto (PIB) de todos os países, o turismo e os serviços relacionados a essa atividade, tal como a gastronomia, foi gerado cerca de $10 \%$ do PIB. Cerca de 200 milhões de pessoas foram empregadas e aproximadamente 467 milhões de turistas, no primeiro semestre de 2012, utilizaram meio de transporte turístico. As receitas internacionais do turismo cresceram cerca de 1.03 trilhões de dólares em 2011, correspondendo a um aumento de 3,8\% em relação a 2010 (UNWTO, 2012).

No entanto, a atividade turística consome recursos em grande escala. Durante o período de um ano, de acordo com National Marine Sanctuaries Program (2006, p. 7), turistas "[...] usam tanta energia quanto o Japão ( 5 milhões de $\mathrm{kWh} / \mathrm{ano}$ ); produzem o mesmo montante de lixo que a França (35 milhões de toneladas por ano); consomem três vezes mais água potável do que a contida no Lago Superior [maior lago da América do Norte, localizado na divisa entre EUA e Canadá] (10 milhões de metros cúbicos por ano)". Devido à enorme escala dos recursos usados pelo turismo mundial, no contexto da atual situação climática, os empreendimentos gastronômicos, dentro da atividade turística, devem desenvolver-se de maneira sustentável, a fim de adequarem-se aos conceitos propostos anteriormente.

A gastronomia é um dos setores dos destinos turísticos que tem a responsabilidade de não permitir que estes sejam vendidos como locais descartáveis, mas que devem ser desenvolvidos de maneira a favorecer a comunidade local e seu ecossistema. Esses destinos devem oferecer experiências originais usando os recursos regionais, pois eles "constituem o patrimônio comum da humanidade, contribuindo para a conservação de áreas de importância mundial cultural e natural, bem como para os processos associados a esses lugares" (BORGES et al., 2011, p. 3). Assim sendo, deve haver uma renovação tecnológica que beneficie a indústria de transporte. A implantação do turismo sustentável e, consequentemente, de medidas que levem a uma gastronomia sustentável é mais custosa do que a do turismo de massa, sem planejamento ou preocupação com o meio ambiente. No entanto, em longo prazo, esse tipo de turismo retorna os gastos extras em lucros duradouros. Os recursos naturais e culturais, se desenvolvidos de forma sustentável, podem, por tempo indefinido, gerar benefícios a todas as partes envolvidas na atividade turística, como no caso da Costa Rica, onde a visitação a áreas protegidas geram mais de USD 1 bilhão ao ano e é a base da economia de diversas regiões (EAGLES et al., 2002).

A gastronomia é responsável por gerar grande parte das atividades correspondentes ao turismo, pois, segundo Yurtseven (2011, p. 17), "[...] para todos os turistas, embora talvez aqui para o novo turista, em especial, todas as facetas da viajem são cruciais e a gastronomia oferece a oportunidade de vivenciar experiências de valor concreto, as quais serão internalizadas pelo viajante". Dessa forma, a sustentabilidade, agregada à experiência turística gastronômica, deve estar presente na atividade gastronômica desde seu planejamento à sua execução.

A importância da gastronomia na vida humana é ímpar, pois seu desenvolvimento deveu-se, em grande parte, às mudanças de hábitos alimentares. O fogo foi o primeiro ato de importância, dando-nos segurança e mudando nossa dieta (WRANGHAM, 2009). Digerir alimentos cozidos é mais fácil do que crus, diminui-se a quantidade de sangue necessária em nosso trato digestivo, possibilitando uma maior alocação de sangue para o cérebro, o qual se desenvolveu em tamanho e capacidade. Reunir-se em volta de uma fogueira levou o ser humano a repartir as refeições e, consequentemente, tornou-nos seres sociáveis. O cultivo de alimentos transformou-nos de nômades em comunidades fixas, e a adição na dieta humana de proteínas animais proporcionou outra evolução cerebral. A gastronomia, portanto, sempre esteve presente e atuante na evolução humana (SCHOENEMANN, 2006). 
Hoje, a experiência gastronômica tomou proporções culturais e artísticas. Seus impactos econômicos, culturais e de saúde, assim como os impactos da agricultura extensiva sobre o meio ambiente, são altíssimos (YURTSEVEN, 2011, p. 17). É preciso reavaliar a maneira como se come e a gastronomia que serve ao turista pode desempenhar um papel de aproximação social global. Ela promove a produção de alimentos locais, transmite conhecimentos culinários, educa as pessoas, promovendo o bem-estar social. Além disso, quando proposta de maneira sustentável, pode ensinar os valores culturais, a apreciação por comida de qualidade, a valorização do trabalho rural da localidade e o modo como os ingredientes de uma refeição foram produzidos e transportados até o prato (SCARPATO, 2002).

No Brasil, os estudos relacionados à sustentabilidade, dentro da experiência gastronômica, estão em estado embrionário. Segundo Nunes (2012, p. 37), "[...] restaurantes sustentáveis ainda são reduzidos, e a grande maioria tem o foco apenas na comida". O maior desafio da gastronomia contemporânea é achar meios de suprir nossas necessidades nutricionais e lúdicas, mantendo a sustentabilidade, já que, de acordo com Poubel, os riscos:

\footnotetext{
[...] que enfrentamos se originam da lacuna entre nossa capacidade tecnológica, nossas relações éticas e nosso entendimento dos sistemas que sustentam a vida [...] é fundamental que encontremos modos melhores, mais seguros e mais inteligentes de suprir tanto as necessidades básicas humanas como, sempre que possíveis e sensatos, os desejos humanos. (POUBEL, 2006, p. 42).
}

No exterior, instituições como a Green Restaurant Association (GRA) fornecem certificados para restaurantes sustentáveis. Os estabelecimentos passam por avaliações e seguem rígidos padrões de qualidade. No Brasil, o Serviço de Apoio às Micro e Pequenas Empresas (SEBRAE) fornece algum tipo de assessoria. Devido à escassez de estudos nessa área, este artigo visa fomentar a discussão sobre a gastronomia sustentável, ressaltando sua importância ao meio ambiente, propondo a realização de estudos aprofundados sobre as variáveis mais pertinentes à gastronomia sustentável. De acordo com os achados da pesquisa bibliográfica, as variáveis que seguem são as mais importantes: Desenvolvimento de Cardápios Sustentáveis; A Sustentabilidade no Contexto dos Ingredientes; Aspectos Construtivos Sustentáveis Relacionados ao Setor da Restauração; Ensino e Treinamento - Fechando o Ciclo da Conscientização.

\section{ENFOQUES PRIMORDIAIS PARA A ABORDAGEM DA SUSTENTABILIDADE NA EXPERIÊNCIA GASTRONÔMICA TURÍSTICA}

\section{DESENVOLVIMENTO DE CARDÁPIOS SUSTENTÁVEIS}

O cardápio possui bom impacto no grau de sustentabilidade de um restaurante. O grande desafio é o uso da criatividade, com ingredientes sazonais ${ }^{2}$ disponíveis localmente. O cardápio pode melhorar a qualidade da imagem de um estabelecimento, funcionando como um importante meio de comunicação no qual o restaurante "apresenta o seu plano de marketing estratégico e serve como a primeira impressão de um consumidor" (MCCALL; LYNN, 2008, p. 440).

Criar um cardápio sustentável é estar conectado não somente com novas tendências gastronômicas, mas também com um método racional e sensível de usar nossos recursos. Um estudo da Universidade de Yale (YALE UNIVERSITY, 2005) mostra um plano de serviço de refeições em que se utilizou, em $22 \%$ do menu da universidade, ingredientes locais e sazonais. Os alunos acharam que a comida, então oferecida, foi a melhor comida já servida em Yale. Isso ajuda a corroborar que, com criatividade, um cardápio sustentável pode ser atraente aos sentidos e bem-sucedido perante seu público alvo. Esse plano redirecionou cerca de USD 1 milhão na economia local (YALE UNIVERSITY, 2005). Essas opções podem gerar lucros imediatos, pois o consumo de produtos orgânicos e sustentáveis está em constante crescimento. Além disso, pode fidelizar clientes que prezam por empreendimentos sustentáveis, propagando ideias e atitudes que sejam condizentes com a atual situação climática e socioeconômica.

Dentro do aspecto geral de planejamento de cardápios, pode-se citar como subtópicos: Dimensionamento adequado das porções e pratos em restaurantes; Uso da sazonalidade de 
ingredientes visando à sustentabilidade; Aspectos culturais da gastronomia como incentivo à sustentabilidade.

\section{DIMENSIONAMENTO ADEQUADO DAS PORÇÕES EM RESTAURANTES}

O correto porcionamento é uma maneira simples de reduzir o impacto ecológico de um estabelecimento gastronômico. A otimização dos recursos existentes gera maior rentabilidade e diminuição da geração de resíduos sólidos. No caso dos ingredientes de alto custo, a otimização das porções é essencial para o sucesso financeiro do restaurante. Os ingredientes provenientes de fontes animais geram altos impactos ambientais, portanto uma redução consciente no tamanho dessas porções é uma medida adequada para um restaurante sustentável, já que, segundo Naqvi e Sejian (2011), a criação de gado é responsável por $18 \%$ do total de emissões dos gases de efeito estufa. O desperdício de ingredientes de alto custo, devido ao porcionamento incorreto, reflete diretamente no bolso do restaurador. Assim sendo, é prudente produzir pratos em pequenas quantidades, de acordo com a demanda, evitando grandes estoques, desperdícios e gastos desnecessários (RABELO, 2012).

O objetivo principal do correto porcionamento dos ingredientes, além de diminuir a quantidade de resíduos, é de minimizar sua produção, pois corrigindo a demanda, representa menor desperdício pela perda direta da matéria prima e menor custo e tempo gasto na operação do restaurante (NRCD, 2010). Quanto mais ingredientes consumidos e desperdiçados, maior é o impacto ecológico do restaurante, pois se usam mais recursos naturais, necessita-se de mais transporte e outros fatores relacionados à produção desses alimentos.

Outro aspecto a ser considerado é o tamanho das refeições, que ajuda a combater a obesidade e outros problemas de saúde relacionados à alimentação. Vale notar, também, que uma grande porção é, na verdade, um incentivo a um consumo exacerbado e ao desperdício, porque, de acordo com Wansink e Kim (2005, p. 242), "[...] pode implicitamente sugerir que o tamanho a ser consumido atende a uma norma de quantidade adequada".

\section{USO DA SAZONALIDADE DE INGREDIENTES VISANDO À SUSTENTABILIDADE}

Com base na pesquisa bibliográfica realizada pelo presente estudo, assim como a análise dos trabalhos utilizados para a elaboração deste artigo, percebeu-se pouca menção sobre sazonalidade dos ingredientes e os seus impactos na sustentabilidade. A sazonalidade é o resultado de milhões de anos de evolução e de seleção natural, de causas sociais e de movimentos culturais que limitam um ingrediente alimentar a um determinado local por um período específico. Usar esses alimentos dentro de seu período sazonal na elaboração de cardápios oferece ao restaurador uma opção de variações de ingredientes conforme as estações climáticas e de sua qualidade superior. Para MacMillan e Fedenburgh $(2009$, p. 4), "[...] isso significa melhor valor, melhor sabor e um negócio melhor para o planeta". A adição de ingredientes que respeitem a sazonalidade em sua produção reflete em menor necessidade de armazenamento - que, em muitos casos, necessitam de temperaturas controladas e de alto custo de embalagem e transporte -, e menos recursos financeiros empregados em sua produção.

As referências culturais favorecem a sazonalidade no sentido de consolidar em algumas preparações o hábito de consumi-las em uma determinada época. Isso agrega um caráter singular a determinados tipos de preparações, adicionando um senso de adequação aos preparos oferecidos pelo restaurante. Além disso, a qualidade de uma preparação consumida dentro do seu período natural de disponibilidade dos seus ingredientes é, segundo McGee (1984), superior à daquela produzida no decorrer do ano todo.

\section{ASPECTOS CULTURAIS DA GASTRONOMIA COMO INCENTIVO À SUSTENTABILIDADE}

O poder que a gastronomia possui em manter vivo o patrimônio cultural é um dos aspectos de sua sustentabilidade. As técnicas culinárias tomam outras proporções, mais do que simples meio de nutrição. Para Rozin (2005, p. 108), os "[...] alimentos assumem funções simbólicas e assumem um significado moral, tornam-se um meio para a expressão estética, dando origem a elaboradas 
preparações e cozinhas que não podem ser justificadas apenas em termos de fatores nutricionais". Um dos focos da gastronomia sustentável deve ser o dos aspectos culturais. Esta é caracterizada por atrativos autênticos e, de acordo com Nilsson et al. (2011, p. 384), ela "[...] deve estar principalmente preocupada com o patrimônio local, o ambiente e a economia social. Preservar cuidadosamente o desenvolvimento do tecido urbano, promovendo o estilo de vida local genuíno é uma das mais importantes questões". Os investimentos em gastronomia sustentável devem ser direcionados para atrativos que fazem do local em que este estabelecimento encontra-se um destino turístico.

Como afirma Queiroz (2008, p. 2), preservar "[...] a gastronomia regional é assegurar a subsistência e manutenção da cultura de um povo". Portanto, o restaurador deve considerar, em seu cardápio, os aspectos culturais do alimento a ser servido, como, por exemplo, o uso de um ingrediente que tenha uma história peculiar com a região na qual se encontra, ou, até mesmo, um material natural regional na confecção física de seu cardápio. Neste sentido, para fomentar a cultura local, deve-se desenvolver uma atividade turística sustentável, direcionada aos valores sociais e culturais, pois o patrimônio gastronômico é visto como um meio de rentabilizar economicamente os pequenos produtores locais de uma maneira sustentável. Consequentemente, o tempo de estadia e os gastos dos turistas com produtos únicos e autênticos são incrementados, promovendo o empreendedorismo local e fortalecendo a identidade da região (TELFER; WALL, 1996).

\section{A SUSTENTABILIDADE NO CONTEXTO DOS INGREDIENTES}

A sustentabilidade no contexto dos ingredientes é outro fator fundamental para a sustentabilidade dentro da experiência gastronômica. Alguns alimentos são mais difíceis de produzir, gastam mais tempo e recursos naturais e emitem uma determinada quantidade de $\mathrm{CO} 2$, causando impacto direto em nossa atual condição ambiental. A agricultura é responsável por $25,5 \%$ das emissões totais de Gases de Efeito Estufa (GEE) e representa $60 \%$ das emissões causadas pelo homem (BLUE MOUNTAINS CITY COUNCIL, 2009).

Dentro do contexto dos ingredientes, podem-se mencionar os seguintes subtópicos: Pegada Ecológica dos Ingredientes: o custo da alimentação ao planeta; Ingredientes Orgânicos: um custo menor ao planeta e à saúde humana; transporte, embalagem e estocagem adequados; Localidade e Autenticidade - Uma experiência turística mais humana e social; Biodiversidade fomentando a sustentabilidade; Técnicas específicas para evitar desperdício de matérias-primas; Características nutricionais dos alimentos visando ao bem- estar e à sustentabilidade.

\section{PEGADA ECOLÓGICA DOS INGREDIENTES: O CUSTO DA ALIMENTAÇÃO AO PLANETA}

A Pegada Ecológica (PE) é uma forma de medir a demanda do ser humano por capital natural em oposição à capacidade da terra de regenerar seus recursos naturais. Segundo Wackernagel e Rees (1996, p. 57), este "[...] conceito fornece uma estrutura intuitiva para o entendimento da base da sustentabilidade". A pegada ecológica auxilia na transparência e na objetividade da sustentabilidade, produz um critério físico em que as tomadas de decisões podem ser empregadas em áreas específicas, de acordo as necessidades das partes envolvidas. Na gastronomia, a pegada ecológica dos alimentos mede o grau do seu impacto ambiental, incluindo-se todos os combustíveis queimados na produção, na fertilização, na irrigação e no transporte desses ingredientes. No caso dos animais (com ênfase no gado), a plantação de milho e algodão (usados como ração) entra no cálculo da pegada ecológica, incluindo as emissões que resultam da conversão de floresta em pastagens e pela emissão de metano, liberada da digestão dos animais e dos adubos. De acordo com a ONU, o cultivo de gado é responsável por $18 \%$ dos gases do efeito estufa (GHG) de todas as atividades humanas (COMPASSION IN WORLD FARMING, 2008).

A produção de carne bovina reduz a biodiversidade, pois milhões de hectares de florestas são desmatados com a finalidade de cultivar uma única espécie. Na América do Sul, 70\% das florestas foram convertidas em pastagem para o gado, e grande parte do restante é utilizada para o cultivo de alimento para os animais (STEINFELD et al., 2006). Portanto, segundo Naqvi e Sejian (2011, p. 19), "[...] reduzir as emissões de gases de efeito estufa provenientes da agricultura, 
especialmente a produção de gado, deve ser uma prioridade". O Gráfico 2 mostra uma comparação da quantidade de CO2 emitida para cada $1 / 2$ Pound (equivalente a aproximadamente $250 \mathrm{~g}$ ) dos alimentos produzidos.

Gráfico 2 - Comparação da Pegada Ecológica de alimentos

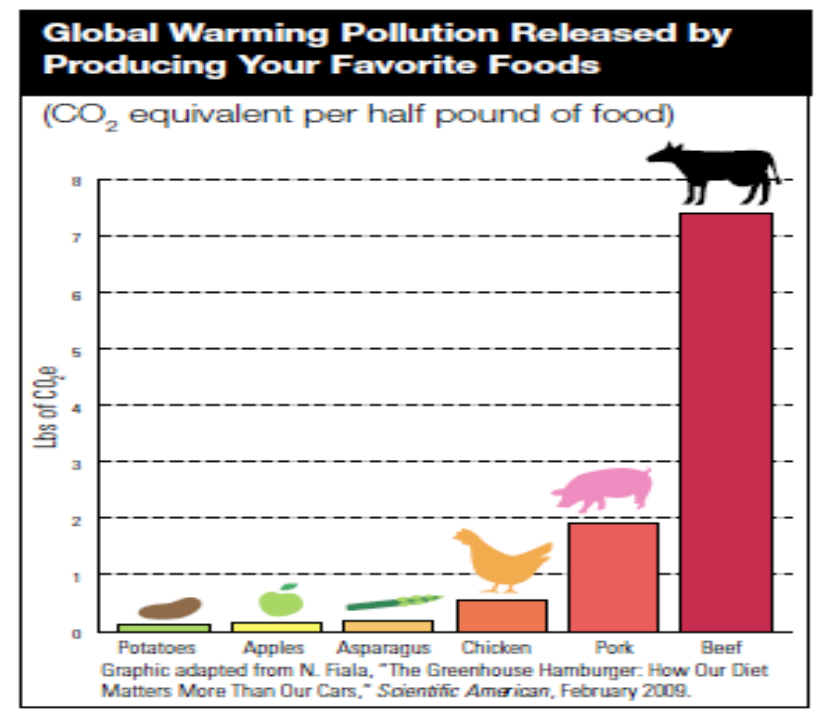

Fonte: NRDC (2010).

A eficiência na produção e no transporte possui impactos significativos no meio ambiente. No entanto, o consumo de alimentos também afeta, diretamente, a produção, alterando, consequentemente, o meio ambiente. Pode-se tomar como exemplo o consumo de carne bovina nos EUA, em que, caso os americanos eliminassem apenas 100 gramas de carne por semana/ pessoa, a redução das emissões de gases do aquecimento global seria equivalente a retirar de 4 a 6 milhões de carros das estradas (NRCD, 2010). Ademais, outros problemas decorrem da produção de alimentos provenientes da agricultura extensiva, como uso excessivo de agrotóxicos, os quais são extremamente prejudiciais à saúde humana.

\section{INGREDIENTES ORGÂNICOS: UM CUSTO MENOR AO PLANETA E À SAÚDE HUMANA}

Os produtos orgânicos suprem a demanda por alimentos saudáveis, de baixo impacto ambiental e alto retorno para o produtor local. O que define os produtos orgânicos, nas palavras de Galvão (2006, p. 16), "[...] é a ausência de agrotóxicos e fertilizantes químicos para o seu cultivo. O produtor deve respeitar normas específicas em todas as etapas de produção, desde a preparação do solo à embalagem do alimento, sempre preservando os recursos naturais". Nos EUA, onde a gastronomia sustentável já está difundida para grande parte da população ${ }^{3}$, as perspectivas para a produção de alimentos orgânicos são de crescimento. No país, em 2006, foram gastos cerca de USD 2.2 bilhões em produtos com certificados de Comércio Justo ${ }^{4}$, um aumento de 42\% em comparação ao ano anterior; e cerca de USD 16,7 bilhões dólares em alimentos orgânicos, quatro vezes mais do que há 10 anos (PULLMAN et al., 2010). De acordo com Ramos Filho (2006), devido às atuais condições climáticas, o "[...] desenvolvimento da cadeia de carne orgânica [...] é um processo irreversível e confirma a tendência mundial sobre o consumo de carne bovina" (RAMOS FILHO, 2006, p. 130). O objetivo dos ingredientes orgânicos é de oferecer opções saudáveis, saborosas, de baixo impacto ambiental e alto retorno socioeconômico, tendo o favorecimento desse tipo de ingrediente sobre outro não orgânico papel importante na difusão do primeiro.

\section{TRANSPORTE, EMBALAGEM E ESTOCAGEM ADEQUADOS}

A produção e o transporte de alimentos possuem impactos diretos no meio ambiente. Em um país desenvolvido, como a Austrália, todo o processo referente à alimentação humana contribui 
para $26 \%$ da poluição de gases do efeito estufa, $47 \%$ do uso de água potável e $60 \%$ da pegada ecológica australiana (BLUE MOUNTAINS CITY COUNCIL, 2009). Assim sendo, é provável que, em países em desenvolvimento como o Brasil, esses números sejam ainda mais alarmantes.

De acordo com o Instituto Brasileiro de Geografia e Estatística (IBGE, 2005), as perdas decorrentes do transporte e estocagem inadequados aproximam-se dos 10\% em média. Para alguns tipos de grãos, como o feijão na Bahia, as perdas ultrapassam 34\% (IBGE, 2005). Portanto, a correta embalagem e a estocagem de alimentos podem aumentar a validade e a qualidade de alimentos, diminuindo o desperdício e, consequentemente, os custos e o impacto no meio ambiente, decorrentes de uso indevido dos recursos naturais.

\section{LOCALIDADE E AUTENTICIDADE - UMA EXPERIÊNCIA TURÍSTICA MAIS HUMANA E SOCIAL}

A autenticidade motiva indivíduos a olharem para a sustentabilidade por meio de uma comparação com a valorização cultural, pois a autenticidade é uma qualidade e diferencial atribuídos a alimentos e práticas culinárias exclusivas. Ela é construída por dois aspectos principais: a existência de um ingrediente alimentar específico de um local e as preparações alimentares resultantes de um processo artesanal. Segundo Yurtseven (2011, p. 19), "[...] ambos repousam sobre um apelo à tradição e cultura: este alimento é o produto de um esforço contínuo e coletivo, estes sistemas alimentares são anteriores aos industrializados e seu valor deriva dessa oposição".

Existe uma demanda por especialidades gastronômicas ou um restaurante que reflita a identidade local. Indivíduos procuram aumentar seus contatos humanos, especialmente quando em férias, por meio de atividades que sejam locais e reais (MULCAHY, 2009). O consumo de comida local diminui o transporte de alimentos, fomenta o desenvolvimento cultural, beneficia o turista com uma experiência rica e autêntica. Isso adere qualidade e marca ao produto, que era, a princípio, simples para a comunidade local e agora possui um senso de exclusividade (TELFER; WALL, 1996). Ademais, a qualidade de produtos importados tende a ser menor do que a dos produtos locais, pois o transporte de longa distância reduz a qualidade de alimentos, devido à necessidade, muitas vezes, de utilização de conservantes químicos, dentre outros do gênero.

Conforme Yurtseven (2011), é na comida local que o turista acha seu contato mais imediato e íntimo com o destino visitado, sendo o melhor e mais fácil meio de experimentar da herança cultural e do patrimônio histórico da localidade. Para esses visitantes, a comida local não só satisfaz o corpo, mas também a alma. Significa adquirir conhecimento aprofundado sobre a cultura local. Já, para Scarpato (2002), isso traz inúmeros benefícios como, além dos já citados, conectar o produtor ao visitante em uma relação saudável e de respeito mútuo, diferente da relação exploradora que se encontra na maioria dos destinos turísticos de massa e sem planejamento sustentável. A autenticidade, a tradição e a culinária local, portanto, estão ligadas, diretamente, à sustentabilidade na experiência gastronômica turística.

\section{A BIODIVERSIDADE FOMENTANDO A SUSTENTABILIDADE}

A preservação de diversas matérias-primas e diferentes métodos de preparos é um incentivo direto à biodiversidade. Alimentos tradicionais fomentam a produção artesanal de alimentos, combatendo a industrialização e a massificação de nossa dieta, pois a padronização oferecida pelo fast food pode homogeneizar os alimentos a ponto de uma completa extinção de diversas espécies e aspectos culturais gastronômicos. A dieta do homem moderno, de acordo com Weiner, baseia-se em:

[...] poucas espécies - menos de 30 plantas são responsáveis pela alimentação de 95\% da população no mundo e no século passado, extinguiram-se 250 mil espécies vegetais, já desde o inicio do século XX, a América perdeu $93 \%$ dos seus produtos agrícolas e a Europa quase $85 \%$. (WEINER, 2005, p. 21).

O movimento Slow Food tem uma ligação direta com a biodiversidade. Originou-se na Itália, em 1986, tornando-se uma organização sem fins lucrativos em 1989. Possui, atualmente, cerca de 80 mil associados. Sua filosofia é "melhorar a qualidade da nossa alimentação e 'arranjar' 
tempo para saboreá-la, isso é uma forma simples de tornar o nosso quotidiano mais prazeroso" (WEINER, 2005, p. 3). A missão dessa organização é mesclar o prazer à mesa com consciência e responsabilidade, defendendo, por meio dos estudos gastronômicos, a biodiversidade na cadeia alimentar e a aproximação entre produtores e consumidores (WEINER, 2005). A luta pela preservação da biodiversidade é proposta por meio de uma ligação direta dos recursos naturais e matérias-primas diversas com o nosso patrimônio gastronômico e cultural.

\section{TÉCNICAS ESPECÍFICAS PARA EVITAR DESPERDÍCIO DE MATÉRIAS-PRIMAS}

Deve-se analisar o desperdício de alimentos em dois momentos: no pré e no pós-consumo. Resíduos pré-consumo são alimentos que não foram ao prato de clientes, decorrentes de baixa qualidade do ingrediente, ou parte dele, no momento da compra ou armazenagem, devendo, portanto, ser descartado. O principal ato para eliminar o desperdício de alimentos pré-consumo é evitar o excesso na compra de ingredientes e cuidado no estoque. Se ainda houver resíduos préconsumo, estes devem juntar-se aos resíduos do momento pós-consumo.

Sobras pós-consumo constituem uma parte importante para a compostagem de resíduos. A compostagem é a maneira mais eficiente no que diz respeito ao manejo de resíduos sólidos. Essa técnica, segundo Santos (2006, p. 36), "[...] é um processo natural de decomposição biológica de materiais orgânicos de origem vegetal ou animal, pela ação de microrganismos. Neste processo de reciclagem da matéria orgânica, o resultado final é um composto estável, similar ao húmus". O valor nutricional desse tipo de adubo é inigualável, funcionando como condicionador de solo e melhora as características deste para o uso agrícola.

Outras técnicas são a reutilização do óleo de cozinha: produto com alto nível de contaminação. Se disposto incorretamente, na rede de esgotos, pode causar entupimentos, exigindo, em alguns casos, o uso de produtos tóxicos para solucionar o problema. Sua reciclagem gera resinas para tintas, sabão, detergente, ração para animais, produção de biodiesel. Reaproveitamento da Água: a água da chuva é reaproveitada por meio de coletores e usada para lavar calçadas, regar jardins e descargas. Coleta Seletiva: os resíduos recicláveis são separados em recipientes identificados e são recolhidos pelas empresas responsáveis. Os resíduos orgânicos são separados dos recicláveis (NUNES, 2012, p. 37).

\section{CARACTERÍSTICAS NUTRICIONAIS DOS ALIMENTOS VISANDO AO BEM-ESTAR E À SUSTENTABILIDADE}

As considerações funcionais e nutricionais das refeições realizadas no cotidiano devem ser diferentes das realizadas dentro de uma experiência gastronômica turística. Em viagem, o indivíduo permite-se algumas exceções e/ou exageros nutricionais que, normalmente, não teria em suas refeições. Entretanto, um restaurante sustentável deve atender ao meio ambiente e também à saúde de seus clientes, pois há:

[...] provas inequívocas de que uma boa alimentação é essencial para a boa saúde durante toda a vida. A boa nutrição ao longo da vida é um grande fator que afeta o crescimento e desenvolvimento da saúde física e mental e qualidade de vida. A má nutrição contribui para doenças crônicas e ameaçadoras, como a doença cardiovascular, diabetes, alguns tipos de câncer e obesidade. (BLUE MOUNTAINS CITY COUNCIL, 2009).

Uma pesquisa reunindo os melhores restaurantes e clubes privados dos EUA mostra que o aumento de consciência quanto à saúde relacionada à gastronomia é crescente. De acordo com Antun e Gustafson (2005, p. 57), "[...] itens de menu saudável devem ser mais do que apenas as saladas. A população americana tornou-se mais consciente na escolha de alimentos, os consumidores exigem escolhas mais saudáveis, com pratos saborosos". 


\section{ASPECTOS CONSTRUTIVOS SUSTENTÁVEIS RELACIONADOS AO SETOR DA RESTAURAÇÃO}

São propostas aqui apenas linhas gerais sobre os aspectos físicos com foco na sustentabilidade, a fim de fomentar o debate de forma a guiar o restaurador na busca por projetos que permitam ter um ambiente físico sustentável. Deve-se lembrar que a sustentabilidade de uma construção não se restringe apenas aos seus impactos no meio ambiente, mas também deve prover o bem-estar de seus ocupantes (NUNES, 2012). Nesse sentido, um estabelecimento que se considere sustentável, preocupado com o bem-estar de seus clientes deve dispor de acesso e equipe orientada para atendimento a pessoas com deficiência.

A etapa de planejamento é, provavelmente, a fase mais importante do desenvolvimento de um restaurante sustentável. Quanto mais tempo e atenção forem gastos nessa etapa, maiores serão os retornos nas etapas seguintes, assim como o menor custo com a realização da obra. A construção civil sustentável é "[...] um sistema construtivo que promove alterações conscientes no entorno, de forma a atender as necessidades de edificação, habitação e uso do homem moderno, preservando o meio ambiente e os recursos naturais, garantindo qualidade de vida para as gerações atuais e futuras" (ARAÚJO, 2012). Em um restaurante sustentável, segundo Araújo (2012), a construção civil sustentável pode ser resumida em nove passos:

Quadro 1 - Diretrizes gerais para uma construção ecologicamente sensível

\begin{tabular}{|c|c|}
\hline Diretrizes gerais & Objetivos específicos \\
\hline $\begin{array}{l}\text { Planejamento } \\
\text { Sustentável }\end{array}$ & $\begin{array}{l}\text { Ser econômica, ter longa vida útil e conter apenas materiais com potencial } \\
\text { para serem reciclados ou reutilizados. Sua meta deve ser resíduo zero. }\end{array}$ \\
\hline $\begin{array}{l}\text { Aproveitamento passivo } \\
\text { dos recursos naturais }\end{array}$ & $\begin{array}{l}\text { Aproveitar sol, vento e vegetação, para promover conforto e bem-estar dos } \\
\text { ocupantes, além de economizar recursos, como energia e água. }\end{array}$ \\
\hline Eficiência energética & $\begin{array}{l}\text { Resolver ou atenuar as demandas de energia geradas pela edificação, } \\
\text { preconizando o uso de energias renováveis. }\end{array}$ \\
\hline $\begin{array}{l}\text { Gestão e economia da } \\
\text { água }\end{array}$ & $\begin{array}{l}\text { Economizar a água; tratá-la localmente e reciclá-la, além de aproveitar } \\
\text { recursos como a água da chuva. }\end{array}$ \\
\hline $\begin{array}{l}\text { Gestão dos resíduos na } \\
\text { edificação }\end{array}$ & $\begin{array}{l}\text { Ser eficiente na gestão dos resíduos gerados pelos usuários da edificação, } \\
\text { por meio de compostagem, no caso da gastronomia. }\end{array}$ \\
\hline $\begin{array}{l}\text { Qualidade do ar e do am- } \\
\text { biente interior }\end{array}$ & $\begin{array}{l}\text { Prover excelentes condições termoacústicas, de forma a melhorar a quali- } \\
\text { dade de vida física e psíquica dos indivíduos. }\end{array}$ \\
\hline Conforto termoacústico & $\begin{array}{l}\text { Criar um ambiente interno e externo com elevada qualidade no tocante à } \\
\text { paisagem local e à qualidade atmosférica e elétrica do ar. }\end{array}$ \\
\hline Uso racional de materiais & $\begin{array}{l}\text { Usar materiais que não comprometam o meio ambiente, a saúde dos ocu- } \\
\text { pantes e que contribuam para promover um estilo de vida sustentável. }\end{array}$ \\
\hline $\begin{array}{l}\text { Produtos e tecnologias am- } \\
\text { bientalmente amigáveis }\end{array}$ & $\begin{array}{l}\text { Resolver localmente ou minimizar a geração de resíduos, que dissemine } \\
\text { consciência ambiental. }\end{array}$ \\
\hline
\end{tabular}

Fonte: Araújo (2012).

Assim como na ecogastronomia, os materiais utilizados na construção devem ser locais, a fim de favorecer a paisagem da região, de integrar clientes com o meio e de diminuir a emissão de poluentes devido ao reduzido transporte. Outros fatores a serem considerados são a durabilidade e a procedência legítima desses materiais. Os materiais mais comuns que possuem alto impacto ambiental, segundo Araújo (2012), são: o PVC, um produto que tem sua origem no petróleo, o qual, quando utilizado e descartado, gera ácido clorídrico e dioxina; o alumínio, cuja extração provoca sérios danos ambientais; os materiais compensados ou de madeira recomposta (MDFs), os quais não são nem recicláveis nem biodegradáveis, e que contêm "adesivos a base de formaldeído" (ARAÚJO, 2012). Podem-se fazer buscas por alternativas para esses outros materiais, tendo como base sua Pegada Ecológica. 


\section{ENSINO E TREINAMENTO - FECHANDO O CICLO DE CONSCIENTIZAÇÃO}

A fim de obter-se maior atenção da comunidade acadêmica nacional, para que estudos e projetos sejam realizados no intuito de promover e avançar a situação da gastronomia sustentável atual, os empreendimentos desse setor devem focar parte de seus esforços além da área artística, trabalhando em conjunto com a comunidade acadêmica e científica. Um segmento dentro da gastronomia que foque seus estudos na saúde alimentar, sem perder atenção artística sobre o alimento, no treinamento de colaboradores e na reeducação alimentar da população, é essencial para que todos os fatores mencionados até então entrem em conjuntura e sejam efetivamente realizados.

Nesse sentido, o movimento Slow Food pode contribuir para uma reeducação alimentar, a qual se encontra ofuscada pelo excesso de açúcares, gorduras e cloreto de sódio da "indústria alimentícia". Todos devem ter "[...] direito a uma alimentação saudável e acessível economicamente e que revolução poderia ser mais deliciosa do que começar a empregar os nossos melhores recursos em ensinar isto às crianças?" (WEINER, 2005, p. 13). O prazer pelo gosto deve ser ensinado a qualquer faixa etária e a gastronomia pode auxiliar as demais ciências em prover alimentação saudável para a população humana, instruindo-as em técnicas, métodos e receitas práticas que possam tornar a alimentação de uma determinada população mais saborosa, prática e saudável. No contexto do ensino e do treinamento, os subtópicos a seguir formam importantes variáveis quando se considera a sustentabilidade dentro de um estabelecimento gastronômico: O papel das instituições de ensino na visão humana sobre o meio ambiente; Eficiência na operação e no serviço - as instituições de ensino ao nível técnico.

\section{O PAPEL DAS INSTITUIÇÕES DE ENSINO NA VISÃO HUMANA SOBRE O MEIO AMBIENTE}

As instituições de ensino são fundamentais para a formação de seres humanos críticos e responsáveis. Consequentemente, são essenciais para o desenvolvimento da sustentabilidade, pois, de acordo com Santos (2006, p. 41), "[...] a Constituição Brasileira, a Educação Ambiental, deve ser contemplada em todos os níveis de ensino [...] o MEC enfatiza que a questão ambiental não deve ser tratada apenas como uma disciplina, mas que ela deve permear todo o curso, criando uma nova competência no indivíduo". Educar em direção à sustentabilidade é mais do que uma tendência e diferencial de ensino, mas sim um dever social. Possuir educação socioambiental, para Ventura (2008, p. 14), "[...] certamente contribuirá na busca de soluções para melhorar a qualidade de vida".

Com a formação profissional de acadêmicos sensíveis e preparados para enfrentar os desafios contemporâneos de forma racional, as instituições de ensino, que desenvolverem grades curriculares permeadas pela sustentabilidade, contarão com um currículo de formação de vanguarda e o aluno capacitado a desenvolver suas habilidades em qualquer frente de trabalho. Esses profissionais promoverão desenvolvimento e crescimento econômico sem deixar de visar a todos os aspectos de nossa sociedade e meio ambiente.

Várias áreas acadêmicas, tais como engenharia, arquitetura e turismo, podem trabalhar em cooperação com a gastronomia, compartilhando conhecimentos e aplicando técnicas e ações, conseguindo, assim, uma maior abrangência de atuação dentro de uma mesma instituição de ensino. Na atividade gastronômica, a sustentabilidade pode ser aplicada a todo o momento em aulas práticas, fazendo com que seja constante e não somente uma disciplina teórica. No ensino de uma instituição consciente e atualizada, "[...] a educação ambiental deve ser um fio condutor, ao longo do qual a sustentabilidade deve ser discutida no decorrer das aulas práticas, como estratégia de melhoria da qualidade de vida, enfatizando a educação como um dos aspectos mais importantes para estas mudanças" (SANTOS, 2006, p. 42). Assim, o verdadeiro papel da disciplina gastronômica (de educar e capacitar profissionais responsáveis, em conformidade com os padrões gastronômicos internacionais) será implantado em sua plenitude. 


\section{EFICIÊNCIA NA OPERAÇÃO E NO SERVIÇO - AS INSTITUIÇÕES DE ENSINO AO NÍVEL TÉCNICO}

A eficiência na linha de produção de um restaurante e nos serviços prestados fecha o ciclo de planejamento sustentável dentro dessa área. Todas as variáveis mencionadas anteriormente podem vir a sucumbir, caso os funcionários estejam despreparados ou desmotivados a agir de maneira sustentável. Todo um planejamento de retenção de custos e de matéria-prima, um correto armazenamento, reutilização de resíduos, enfim todos os aspectos da gastronomia sustentável dependem da operacionalização dessas tarefas por meio da brigada de trabalho ${ }^{5}$. Essas diretrizes só poderão ser implementadas caso os colaboradores estejam cientes e preocupados com as políticas de sustentabilidade que o empreendimento está empregando. Em um processo de conscientização ambiental, é essencial o ensino de técnicas e métodos de trabalho. O grande desafio concentra-se, de acordo com Nunes (2012, p. 36), "[...] no alto índice de rotatividade dos funcionários, o que dificulta os investimentos na formação de competências e circulação do conhecimento".

Portanto incentivos devem ser realizados a fim de motivar a brigada de trabalho, promovendo uma carreira aos colaboradores da gastronomia, pois muitos procuram um emprego na área sem perspectiva de crescimento e apenas como algo temporário. Uma abordagem gerencial de incentivos em longo prazo tende a reverter a alta rotatividade e, em alguns casos, o descaso de membros da brigada de trabalho para com a qualidade prestada pelo empreendimento. No caso da sustentabilidade, esse aspecto tende a ser negligenciado por uma brigada despreparada, por tratar-se de um assunto novo e, muitas vezes, desconhecido à grande parte dos colaboradores da gastronomia.

\section{CONCLUSÃO}

Os estudos sobre sustentabilidade na gastronomia estão em seus primeiros momentos. Mesmo internacionalmente, há um grande número de áreas específicas de pesquisa a serem desenvolvidas e discutidas. Há, atualmente, um crescente aumento da percepção da alimentação em relação à saúde e ao bem-estar social, e da gastronomia como atrativo turístico e atividade cultural fundamental ao ser humano. Finalmente, há, também, uma consciência maior sobre nosso papel e influência em nosso meio ambiente. Alinhando esses fatores, percebe-se a importância da sustentabilidade na experiência gastronômica turística.

Dentro desse contexto, este artigo propôs reunir os principais fatores que possam vir a influenciar a gastronomia a se tornar uma atividade sustentável. Os cardápios sustentáveis possuem bom impacto no meio ambiente, pois usam ingredientes locais e sazonais, trazem benefícios diretos na qualidade da imagem de um estabelecimento e fidelizam clientes, gerando lucros imediatos. O dimensionamento adequado das porções otimiza os ingredientes que são utilizados, gera maior rentabilidade, diminui a quantidade de resíduos, além de auxiliar no combate dos problemas de saúde relacionados à alimentação. O fator sazonalidade dos alimentos deve ser respeitado, caso se procure atingir a sustentabilidade em um estabelecimento gastronômico, pois esta promove o uso de ingredientes frescos, consequentemente de menor tempo de transporte e estocagem, além de salientar aspectos culturais relacionados a alguns tipos de alimentos.

Os aspectos culturais podem incentivar a sustentabilidade por meio da manutenção do patrimônio cultural e ambiental de alguns ingredientes e técnicas culinárias. A Pegada Ecológica dos alimentos ajuda a mensurar o impacto de cada ingrediente sobre nosso planeta, dando, assim, uma base de como proceder no uso de cada um deles. Deve-se fomentar a eficiência na produção dos alimentos, assim como otimizar o transporte, a embalagem e a estocagem de ingredientes, a fim de obter uma pegada ecológica menor, criando um sistema sustentável e de custos baixos. A autenticidade e a localidade de uma experiência turística gastronômica favorecem o produtor e o meio ambiente local, dando ao turista um contato imediato, íntimo e verdadeiro com o local visitado. A biodiversidade prega a preservação de diversos ingredientes, dos alimentos tradicionais e dos aspectos culturais ligados a estes, tendo somente a contribuir para a gastronomia sustentável.

Outro importante aspecto que leva um estabelecimento em direção à sustentabilidade são as técnicas para evitar desperdício de ingredientes e o uso dos resíduos como composto orgânico. 
As características nutricionais balanceadas visam ao bem-estar dos clientes, portanto contribuem para o conceito de sustentabilidade. Os aspectos construtivos compõem grande parte do impacto ambiental de um empreendimento gastronômico no meio ambiente, portanto as variáveis seguintes devem ser consideradas: planejamento sustentável, aproveitamento passivo dos recursos naturais, eficiência energética, gestão e economia da água, gestão dos resíduos na edificação, qualidade do ar e conforto acústico, uso racional de materiais e, finalmente, uso de produtos e de tecnologias ambientalmente amigáveis.

Fechando o ciclo de uma administração de um empreendimento gastronômico voltado à sustentabilidade, deve-se incentivar o ensino e o treinamento de acadêmicos e a brigada de trabalho. Esse aspecto visa promover estudos que venham contribuir com o desenvolvimento da gastronomia sustentável e qualificar a mão de obra para que os esforços de planejamento sejam mantidos em sua execução.

Esse trabalho propõe abrir a discussão sobre o assunto no âmbito nacional, além de auxiliar, via orientações gerais (as variáveis elencadas anteriormente), o restaurador que procura o significado da sustentabilidade gastronômica e como dar os primeiros passos em sua direção. Outro fator de grande importância é a da preferência dos turistas para destinações e estabelecimentos que tenham efetivamente uma preocupação na questão da sustentabilidade. O caminho para a sustentabilidade não é fácil, pois requer construções extras que podem trazer maiores custos, exige mão de obra qualificada e planejamento extenso, dentre outros. Contudo os retornos financeiros já estão presentes na indústria gastronômica atual e a recompensa maior é a de se viver em um mundo equilibrado, saudável e mais justo.

\section{NOTAS}

Corpo científico criado em 1988 pela Organização das Nações Unidas (ONU), tendo como missão fornecer avaliações científicas, técnicas e socioeconômicas atuais sobre o risco das mudanças climáticas causadas pelas atividades humanas.

A sazonalidade está ligada às estações do ano. Os ingredientes sazonais são aqueles que se encontram disponíveis por apenas um determinado período durante o decorrer de um ano, em vez do ano todo.

Percebeu-se, não somente por meio de experiência profissional e pessoal, que a gastronomia sustentável encontra-se bem difundida perante grande parte da população norte-americana, pois a maioria dos artigos pesquisados, reportagens, dissertações e teses encontradas sobre sustentabilidade gastronômica foram de origem norte-americana.

É um sistema que permite pessoas identificar produtos que satisfaçam normas ambientais, trabalhistas e de desenvolvimento. Supervisionada pela Fairtrade International (FLO), uma instituição de certificação e auditoria independente a fim de garantir que as normas sejam cumpridas.

A brigada de trabalho é o conjunto de funcionários de um empreendimento gastronômico. Essa brigada é dividida entre a de serviço e a de produção. A primeira são os funcionários que executam o atendimento no salão de refeições do restaurante. A última são os funcionários responsáveis pela realização dos pratos servidos pelo empreendimento gastronômico.

\section{REFERÊNCIAS}

ANTUN, J. M.; GUSTAFSON C. Menu Success: a menu analysis of awarded fine dining restaurants and private clubs. Journal of Culinary Science \& Technology, vol. 4. Philadelphia, 2005.

ARAÚJO, M. A. A Moderna Construção Sustentável. IDHEA - Instituto Para o Desenvolvimento Da Habitação Ecológica. Disponível em: <http://www.idhea.com.br/pdf/moderna.pdf>. Acesso em: 20 set. 2012.

BLUE MOUNTAINS CITY COUNCIL. Healthy And Sustainable Food Choices - Guidelines For All Council Managed Food Services. Sidney: NSW Health, 2009.

BORGES, M. A. et al. Sustainable tourism and natural world heritage. International Union for Conservation of Nature. Gland - Suíça, 2011. 
COMPASSION IN WORLD FARMING. Global Warning: Climate Change \& Farm Animal Welfare, Summary Report. Surrey, 2008.

EAGLES, P. F. J. et al. Sustainable tourism in protected areas. World Commission on Protected Areas (Wcpa), United Nations Environment. Cambridge, 2002.

ELKINGTON, J. Cannibals With Forks: The Triple Bottom Line of 21st. Oxford: Capstone Publishing, 1997.

GALVÃO, A. K. L. Fatores que afetam o interesse de compra de produtos orgânicos em supermercados de Manaus. Tese de Mestrado da Universidade Federal do Rio Grande do Norte (UFRN). Natal, 2006.

HANSEN, J. et al. Global Temperature Change. PNAS, v. 103, n. 39. Washington, D.C., 2006.

HIRSCH, R. L. et al. Peaking Of World Oil Production: Impacts, Mitigation, \& Risk Management. New York: Nova Science Publishers, 2005.

HUBBERT, M. K. Nuclear Energy and the Fossil Fuels. Shell Development Company. Texas, 1956.

IBGE. Perdas de grãos, no Brasil, chegam acerca de 10\% da colheita. Disponível em: <http:// saladeimprensa.ibge.gov.br/noticias?view=noticia\&id=1\&busca=1\&idnoticia=330>. Acesso em: 12 jul. 2013.

IPCC. Climate Change 2007: Synthesis Report - Fourth Assessment Report of The Intergovernmental Panel on Climate Change [Core Writing Team, Pachauri, R. K and Reisinger, A. (Eds.)]. Geneva, Suíça, 2007.

MACMILLAN, T.; FEDENBURGH, J. What should supermarkets do about seasonal food? Food Ethic Council. Brighton, 2009.

MASLIN, M. Global Warming - A Very Short Introduction. 2. ed. Oxford, 2009.

MCCALL, E. M.; LYNN, A. The effects of restaurant menu item descriptions on perceptions of quality, price, and purchase intention. Oxford: Journal of Foodservice Business Research, v. 11, 2008.

MCGEE, H. On food and cooking: The Science and Lore of the Kitchen. Scribner, New York, 1984.

MULCAHY, J. D. Making the case for a viable, sustainable gastronomic tourism industry in Ireland school of history and politics. Adelaide: University Of Adelaide, 2009.

NAQVI, S. M. K.; SEJIAN, V. Global Climate Change: Role of Livestock. Avikanagar: Asian Journal of Agricultural Sciences, v. 3, n. 1, 2011.

THE NATIONAL ACADEMIES PRESS. America's Climate Choices, 2011. Disponível em: <http://www.nap. edu/catalog.php?record_id=12781>. Acesso em 15 jun. 2013.

NATIONAL MARINE SANCTUARIES PROGRAM. Sustainable Tourism Concepts. NMSP, 2006.

NASA. National Aeronautics and Space Administration. Goddard Institute for Spacial Studies. Global Annual Mean Surface Air Temperature Change. Disponível em: <http://data.giss.nasa.gov/gistemp/ graphs_v3/>. Acesso em: 12 jun. 2013.

NILSSON, J. H. et al. Cittaslow eco-gastronomic heritage as a tool for destination development. Current Issues in Tourism, v. 14, n. 4, 2011.

NRDC. Natural Resources Defense Council. Eat Green: Our everyday food choices affect global warming and the environment. 2010. Disponível em: <http://www.nrdc.org/globalwarming/files/eatgreenfs_feb2010. pdf $>$. Acesso em: 10 jun. 2013.

NUNES, R. Gastronomia sustentável. Revista Científica da Faculdade das Américas, ano VI, n. 1, São Paulo, 2012.

PNAS. Joint Science Academies' Statement: Global response to climate change. Disponível em: <http:// nationalacademies.org/onpi/06072005.pdf>. Acesso em: 10 out. 2012.

POUBEL, R. O. Hábitos alimentares, nutrição e sustentabilidade. Dissertação de Mestrado em Desenvolvimento Sustentável. Universidade de Brasília, Brasília, 2006. 
PRUGH, T.; ASSADOURIAN, E. What is sustainability, anyway? World Watch Magazine, v. 16, n. 5, 2003.

PULLMAN, M. E. et al. Sustainability practices in food supply chains: how is wine different? Journal of Wine Research, v. 21, n. 1, 2010.

QUEIROZ, F. L. N.; Alimentação regional saudável em unidades produtoras de refeições do sudeste brasileiro. Universidade de Brasília. Brasília, 2008.

RABELO, D. Idéias de negócios sustentáveis - restaurantes naturais. São Paulo: SEBRAE, 2012.

RAMOS FILHO, F. Qualidade na cadeia da carne bovina: o caso da carne orgânica. Rio de Janeiro: UFRRJ, 2006.

ROZIN, P. The meaning of food in our lives: a cross-cultural perspective on eating and well-being. Journal of Nutrition Education and Behavior, v. 37, n. 2, 2005.

SANTOS, C. M. M. O gerenciamento de resíduos sólidos no centro universitário. SENAC. Taubaté, 2006.

SCARPATO, R. New Global Cuisine: the perspective of Postmodern Gastronomy Studies. Rmit University, Melbourne, 2003.

SCHOENEMANN, P. T. Evolution of the size and functional areas of the human brain. Annual Review of Anthropology, v. 35. Palo Alto, 2006.

STEINFELD, H. et al. Livestock's long shadow: environmental issues and options. Food and Agriculture Organization of The United Nations. Roma, 2006.

TELFER, D. J.; WALL, G. Linkages between tourism and food production. Annals of Tourism Research, v. 23, n. 3. Elsevier, 1996.

UNWTO. 415 million tourists expected worldwide in the May-August peak season. Disponível em: <http://media.unwto.org/en/press-release/2012-07-09/415-million-tourists-expected-worldwidemay-august-peak-season>. Acesso em: 28 out. 2012.

VENTURA, S. N. Educação Ambiental: uma análise da aplicabilidade no curso de Gastronomia. Dissertação de Mestrado do Curso de Ciências Ambientais. Universidade de Taubaté. Taubaté, SP: 2008.

WACKERNAGEL, M.; REES, W. E. Our ecological footprint: reducing human impact on earth. New Society Publishers, Canada, 1996.

WANSINK, B.; KIM, J. Bad Popcorn In Big Buckets: Portion Size Influence Intake As Much As Taste. Journal Of Nutrition Educational Behaviour, V. 37, N. 5. Nova Iorque, 2005.

WCED. World Commission on Environment and Development. Our Common Future. Oxford University Press. Oxford, 1987.

WEINER, S. O Manual Slow Food. 2. E. Itália: Slow Food Editore, 2005.

WRANGHAM, R. Catching Fire: how cooking made us human. New York: Basic Books, 2009.

YALE UNIVERSITY. Yale Sustainable Food Project - Annual Report. New Haven, EUA. 2005. Disponível em: <http://www.yale.edu/sustainablefood/SFPreport_low.pdf.03>. Acesso em: 25 set. 2012.

YURTSEVEN, H. R. Sustainable Gastronomic Tourism in Gokceada, local and authentic perspectives. International Journal of Humanities and Social Science, v. 1, n. 18, 2011. 